\title{
Is Learning Only a Cognitive Process? Or Does It Occur in a Sociocultural Environment?: "Constructivism" in the Eyes of Preschool Teachers
}

\author{
Duygu Saniye Öztürk \\ Correspondence: Duygu Saniye Öztürk, Faculty of Education, Abant Izzet Baysal University, Bolu, Turkey \\ Received: December 28, 2015 Accepted: January 18, 2016 Online Published: February 16, 2016 \\ doi:10.11114/jets.v4i4.1268 \\ URL: http://dx.doi.org/10.11114/jets.v4i4.1268
}

\begin{abstract}
This study aims to identify the views of preschool teachers about learning within the framework of the cognitive and sociocultural constructivist approach and reveal the practical applications of constructivist learning in the 2006 Preschool Curriculum. Participants were ten preschool teachers working at three preschools in Bolu, Turkey and data were collected from focus group interviews with these teachers. According to the findings preschool teachers' views about children's learning through school activities were primarily in line with the sociocultural constructivist approach. The majority of teachers were found to believe constructivist learning could best be realized in preschool classes through open-ended activities.
\end{abstract}

Keywords: cognitive constructivism, sociocultural constructivism, preschool education teachers, preschool curriculum

\section{Introduction}

The effort of a child to explore and understand the environment from infancy through the process of growth is an effort to learn. This effort to learn forms the foundations of the language, physical skills, social understanding and emotional development needed in the future (DeVries, Zan, Hildebrant, Edmiaston, \& Sales, 2002). These acquisitions take part in a process during which children try to experience the world around them and collect information. This process is at the same time an example of constructivist learning.

Constructivism underlines the importance of an individual's knowledge, beliefs and skills in the experience of learning, and defines the construction of new learning as a combination of preparedness for learning, new information and previous learning (Epstein, 2002; Airasian \&Walsh, 1997). Learning is a result of an activity and self-organization. Learning supportsthe development of cognitive structures. As students try to make meaning, they make developmental changes in their points of view, or construct big ideas. Big ideas usually necessitate a reorganization of previous learning (Fosnot \& Perry, 2005). Then, constructivism attempts to define how structures, language, activity and meaning-making emerge. Constructivism is therefore thought to be a theory related to information and learning, and explain both what "knowing" is and how "learning" occurs (Fosnot, 2005).

The recent interest in the constructivist approach as a learning theory has created debates between those who focus on the individual cognitive structuring process in learning and those who focus on social and cultural effects (Fosnot \& Perry, 2005; Duffy \& Cunningham, 1996; Wong, 2008). The individual cognitive approach was derived of Piaget's theory. Piaget is one of the most influential pioneers of the constructivist approach. In his own terms, he is a genetic epistemologist interested in the formation of information and cognitive development. In his studies, Piaget concluded that knowledge is born out of individual constructions by learners (Brooks \& Brooks, 1993). He states that human cognition is a dynamic set of cognitive structures helping to make meaning of perceptions. These structures develop within a state of cognitive complexity as people mature, interact to learn about the world, and gain more experience (Brooks \& Brooks, 1993). In other words, Piaget claims that information that humans understand and use cannot be transmitted to them from the outside; instead, they need to construct their knowledge themselves. He also claims that cognitive schemas are formed by the processes of assimilation and adaptation. These processes are an effort of research by the child until "equilibrium" is achieved. The assimilation and adaptation processes are also one during which children strive to adapt new information into their existing structures, and is at the same time formation of learning. Piaget expects teachers to engage in class work to trigger the process in students (Powell \& Kalina, 2009). From this perspective, ambiguity as a stimulus or the teacher and other students as the source of confusion are important for individual learning (Powell \& Kalina, 2009). People offer learners an effective and ready source of confusion during the 
process of understanding (Duffy \& Cunningham, 1996). The focal point is then the individual within a group, and cognition occurs in the individuals head. However, in contrast to the individual constructions that Piaget and von Glasersfeld focus on, the sociocultural approach emphasizes the socially and culturally constructed structure of cognition (Duffy \& Cunningham, 1996).

Vygotsky laid the theoretical foundation of the sociocultural approach. The main topic of Vygotsky's work concerned the effects of social interaction, language and culture on learning (Fosnot \& Perry, 2005). Vygotsky argues that children's social environment plays an important role in cognitive development. Children start to learn from the people around them and their social world. Children's environments and culture determine the type and quality of the stimuli offered to them. Thus, the source of cognitive development is the interaction between people and culture, before individual psychological processes (Senemoğlu, 1997). Vygotsky (1997), stresses adults and teachers play a critical role in children's learning processes. Vygotsky believed that children needed adult guidance but also thought that exploring things and learning from peers is also very important for students. When children work interactively with other children or adults, they learn concepts and ideas that they would otherwise not be able to learn on their own (Epstein, 2002). This can also be explained with Vygotsky's zone of proximal development (ZPD), which is defined as the area where learning occurs when a child receives help as he learns a concept in the classroom (Powell \& Kalina, 2009). Students construct their knowledge, make their ideas concrete, and understand better when they are helped by more knowledgeable people such as teachers within their ZPD. This gradually raises students' awareness levels and they become able to organize their learning via metacognition. In this approach, learning is seen as a social activity shared through in-class interactions (Watson, 2001). Therefore, observing the concept development of students in cooperation with an adult is a better way of seeing their competencies (Fosnot \&Perry, 2005).

In summary, in socioculturally based constructivist pedagogy, teachers and children become part of a process in which they actively construct their knowledge via interacting with time, space, objects and humans (Nuttall, 2003). Thus, socioculturally based constructivist pedagogy sees learning as an active process maintained through meaningful social interactions of which the learner is a part (Hedges, 2000).

As discussed above, cognitive and sociocultural approaches on knowing and learning have different explanations and arguments. Their conflict is whether learning is an effective cognitive organization process or one of enculturation. In other words, cognitive constructivism claims that ideas are constructed in the brain via an individual process, while social constructivism argues that they are constructed via interacting with teachers and peers. Teachers with constructivist pedagogy perspective should know these different approaches to learning and choose their own educational orientations. Indeed, learning occurs with individual effort as students construct their knowledge, but help from teachers play an important role in furthering their learning. Teachers' thoughts about how learning occurs also determine their in-class strategies and stance. Therefore, a child-centered educational approach has been adopted and implemented in the preschool system in Turkey since the 2000's, and it has been necessary to determine constructivist-minded preschool teachers' views on learning and their classroom orientations.

The aim of this study is to identify preschool teachers' views about how child learning occurs within the framework of the constructivist approach. At the same time, practical applications of constructivist learning were also determined within the main approach of the Preschool Curriculum which was developed and put into use by the Ministry of National Education in 2006 (MEB, 2006).

\section{Method}

Aiming to determine the constructivist learning views of preschool teachers, this study is a qualitative research. To collect data, the focus group study technique was used. Focus group interviews refer to the group interview technique, their borders are drawn by a certain topic, and different from other techniques, group dynamics emerge in these interviews as a result of the interactions between group members. Compared to individual interviews, such group processes yield deeper level and richer information about the study problems owing to their dynamism and creativity (Stewart, Shamdasani \& Rook, 2007). The aim of focus group interviews is to obtain deep, multidimensional and qualitative information about a pre-specified topic and participants' views, experiences, tendencies, ideas and emotions about specified topic (ASA,1998). As this technique was thought to enable teachers to reveal their views, experiences, and tendencies about learning and constructivist approach in a more relaxed and interactive way, it was utilized in this study.

\subsection{Formation of Focus Groups and Data Collection}

To begin with, a question form was prepared in line with the aims of the study to be used in focus group studies. The form consisted of questions which allowed preschool teachers to share their observations of activities they carried out with children at school, and explain the concepts of learning and constructivism by using their observations and experiences. The form also consisted of questions where teachers could state their views about the theoretical aspect of 
the national preschool curriculum they were following and whether the program allowed the preparation and implementation of constructivist activities. The question form had seven open-ended questions in total. After preparing the focus group question form, a pilot trial was done with five preschool teachers working in Bolu. These teachers were contacted to identify a common day and time when they were free to participate in the trial run, as well as a preschool which was easily accessible by all of them. To prevent interfering with school instruction, the pilot trial was scheduled for a Saturday. Certain problems that emerged during the trial regarding the recorder and the question form were noted. These were then amended as a measure before the final implementation.

The focus group interviews were planned in two sessions attended by five teachers each. This was deemed necessary so that teachers would have the opportunity to express their views more comfortably and in more detail. The trial teachers were excluded from the ten teachers finally identified to take place in these two sessions.

The study group comprised preschool teachers working at three kindergartens in the northwestern Turkish province of Bolu. A total of thirteen teachers were working at these three institutions. Of these teachers, ten four-year university graduates were chosen and divided into two five-person focus groups. All of these teachers participated on a voluntary basis. Thus, two focus group discussions of five teachers each were established. Table 1 presents demographic information about the teachers. The discussion sessions took place on a Saturday in the preschool where the pilot trial was held. The teachers were contacted prior to the sessions to give information about the topic and contents of the study. Focus group discussions lasted one and half hour in each group. During the discussions, both note-taking and audio-recording was done. The focus group discussions were directed by the researcher; however, an academic who had been informed about the study also attended the sessions for note-taking purposes.

Table 1. Demographic characteristics of teachers

\begin{tabular}{lllll}
\hline Name & Gender & Years of experience & School name & $\begin{array}{l}\text { Children s age group } \\
\text { (in years) }\end{array}$ \\
\hline A1 & F & 3 & C & 4 \\
A2 & F & 5 & C & 5 \\
A3 & F & 4 & C & 6 \\
A4 & F & 6 & D & 4 \\
A5 & F & 3 & D & 5 \\
B1 & F & 5 & D & 6 \\
B2 & F & 5 & E & 4 \\
B3 & F & 4 & E & 5 \\
B4 & F & 7 & E & 6 \\
B5 & F & 9 & E & 5 \\
\hline
\end{tabular}

Note: $\mathrm{F}=$ Female

\subsection{Data Analysis}

Audio recordings from focus group discussions were transcribed and reported. These reports were checked against the notes kept during the sessions and a detailed written form was obtained. The written forms were later submitted for the examination of three teachers who participated in the study, and the transcripts were confirmed as accurate. This form was then examined with a code list prepared in line with the study topic and questions, and coding was undertaken. To illustrate, data were recorded according to the code list including concepts such as "individual effort", "participating in activities", "socialization", "individual preference", "adult support in learning" and "cultural traits". Following this, themes were built in line with the codes, and the relationships between these themes and the study questions were reconsidered and organized. In the last stage, data were described according to the themes, examples were given where necessary, and interpretations were made. Teachers in the first session were referred to as A1,A2,A3,A4,A5 and those in the second session as B1,B2,B3,B4,B5.

\section{Results}

When data were being analyzed, four main themes were determined to describe preschool teachers' understanding of constructivist learning. These themes, given in Table 2, were "cognitive/individual view", "sociocultural view", "learning through structured activities" and "learning through open-ended activities".

Table 2. Preschool teachers' perceptions about constructivist learning

\begin{tabular}{ll}
\hline Themes & Number of teacher views \\
\hline Cognitive/personal view & 4 \\
Sociocultural view & 6 \\
Learning through structured activities & 3 \\
Learning through open-ended activities (by spontaneous experiences) & 7 \\
\hline
\end{tabular}

Of the ten teachers in the study group, four ( A2, A4, B1, B5) agreed that child learning is in fact an individual effort 
and occurs when children just discover as a result of interacting with materials. The remaining six teachers (A1, A3, A5, B2, B3, B4) emphasized that learning occurs through individual interactions and children's social interactions. Ten teachers supported constructivist learning as the 2006 Preschool Curriculum that they were using is a developmental program. Seven teachers (A1, A3, A4, A5, B2, B3, B4) stated that learning via self-started activities is more effective, while three (B1, B5, A2) stated that they could control learning via fully structured daily activities.

\section{Discussion}

As shown in Table 2, preschool teachers' views about the concept of constructivist learning were examined under four themes considering the main approach of the 2006 Preschool Curriculum. Below, the data obtained are described and interpreted under these themes.

\subsection{Cognitive/Individual View}

Four of the preschool teachers ( A2, A4, B1, B5) claimed that cognitive processes are important in learning in the constructivist approach. While they agreed that social life also affects children's learning, they put the main emphasis on experiences gained through individual effort. One teacher stated the following:

This is my third year in the profession. I observe children during activities and I see that the more they engage in materials, the more excited they become when they talk about their thoughts and feelings about what they are doing. Even though the material may be something they already know, this $i$ still the same. For instance, when I brought ice trays to class, I left the children alone with the trays and just observed what they did with ice before I explained what it is and how it forms and changes. My pupils are 4 years old. As if they had never seen ice before, they touched it, tasted it, shrieked when it melted, and told each other about their feelings. Meanwhile, I thought it would have no meaning for me to interfere with this experience. They had already told each other everything I intended to say about ice. If we leave them alone with objects and events in a way they can use their senses, we will easily see how they discover. (A2)

This teacher (A2) can be seen to tend towards the idea that cognitive structures are the main factor in the individual process as children learn. Teacher A2's view parallels the discourse of the individual/cognitive view, which is one of the two branches of the constructivist approach and has been born out of Piaget's theory. This approach stresses that individuals engage in a constructivist activity as they make an effort to make sense of the world. According to cognitive theorists, learning is a process that learners entirely construct by themselves as they strive to adapt their experiences to their life and solve conflicts (Duffy \& Cunningham, 2001). Individual experiences emerge here as a critical component in meeting the expectations of individuals or solving conflicts. This is obvious from the teacher's following sentences: "As if they had never seen a piece of ice before, they touched it, tasted it, shrieked when it melted, and told each other about their feelings. Meanwhile I thought that it would have no meaning for me to enter this experience". This teacher attributes child learning entirely to their own experiences and the resulting inferences they make. On the other hand, the main tendency of the teacher in activities is enabling children to directly interact with materials, rather than offering direct information about the materials, events and phenomena. This tendency is clear in the following part of the teacher's statement: "For instance, when I brought ice trays to class, I left my pupils alone with the trays and just observed what they did with the ice before I explained what it is and how it forms and changes". Piaget also proposed in his cognitive development theory that individuals cannot be taught information they can automatically understand and use, and instead they should construct their own knowledge through their experiences. Experiences enable the formation of mental images in individuals' minds (Epstein, 2002).

Below is a statement from another teacher who also mentioned similar cognitive/individual constructivist learning ideas:

To me, "constructivism" is allowing children to engage in materials and express the process that they undergo with them, rather than using these materials to give direct information. Working with materials is particularly important for preschool children. Getting thoughts and talking about them shows that their knowledge is being formed. For instance, when I have all of them do the same experiment but they do not all get the same results, I see that they learn a lot by questioning the reasons for this and compare their results to those of others. (A4)

This statement explains constructivist learning as the constructions which appear in children's minds as a result of their efforts and the outward expression of these. Thus the emphasis is on individuality and cognitive processes.

Both of the teachers quoted above seemed to think that the cognitive constructivist view had a role in the learning process. Piaget stated that teachers should arrange an environment conducive to making their students think and discover (Brooks \& Brooks, 1993). Both teachers quoted above implied that teachers ought to prepare the materials and environmental facilities to make children learn, and allow them to gain experiences with these materials. 


\subsection{Sociocultural View}

Preschool teachers' views and tendencies showed that most of them adopted the sociocultural constructivist view (A1, A3, A5, B2, B3, B4). In addition to the opinions of teachers tending towards the individual/cognitive constructivist view, others added when explaining constructivist learning that children learn from interacting with others as well as from materials. A teacher who held this view said the following about constructivism:

What attracts my attention most in activities is that the children are more willing, active and excited during group activities. What I mean is, when I give them something to do with their peers as opposed to something to do on their own, they learn more from each other. I believe that learning happens when children are supported in a social environment. When working with peers or the teacher, they can more easily construct their ideas and compare them to those of others because they feel group membership. (B3)

The main element in this view is the need for an environment conducive to social participation as children learn. Here, the concepts of social environment and participation which lie at the core of Vygotsky's sociocultural constructivist approach come to the foreground. This approach stresses that there is socialization and enculturation in cognitive activity, and defines learning as introducing individuals to cultural practices, special cases, limitations and possibilities (Vanderstraeten \& Biesta, 2005). Teacher B3's words that children learn much from each other when allowed to work together entirely overlap with the definition of knowledge in the sociocultural approach. According to the sociocultural approach, knowledge is formed with the interaction of individuals and the social environment they live in. Social constructivists argue that knowledge has social content and cannot be formed independently of individuals' social structure (Airasian \& Walsh, 1997). This view supports peer culture and peer learning. As shown by previous studies, when children sit in a classroom with their peers, discuss in groups, make jokes with each other and compete, they can both construct their knowledge and form a stronger identity (Lash, 2008; Hatch, 1989).

In addition to this teacher's (B3) thoughts, another one holding the same view stated that not only peers but also teachers exist in a child's social environment.

I think that teachers also have an important place in the sociocultural structure we are discussing here. Children need to be together but teachers also need to support them. Instead of offering activities to children, I join them as if I'm one of them. (A5)

The emphasis that teacher A5 makes on the concept of "teacher" is present in the sociocultural approach too. Socioculturally-based constructivist pedagogy refers to a process in which teachers and children actively construct their knowledge by interacting with time, space, objects, and humans (Nuttall, 2003). Teachers play a major role in learning using this approach. Teachers and other adults arrange for the participation of children in activities, and offer them thought-provoking and supportive resources (Mallory \& New, 1994). Mentioned also by teacher A5, "adult support" has an important place in the sociocultural approach. In the social constructivist approach, teachers guide students as they approach problems, encourage them to work in groups, and support them with their recommendations (Epstein, 2002).

\subsection{Learning with structured activities}

In focus group discussions about how best constructivist learning can be used in classrooms, very few preschool teachers (B1, B5, A2) defended the argument of learning via structured activities. This argument states that the teacher's day should be planned around activities, and this is the only way to control whether learning is materializing. In structured activities, the teacher management method becomes important. The teacher has a major role in preparing, starting, and ending activities. However, this does not agree with the main characteristics of the child-centered constructivist approach. The function of the teacher in constructivist teaching is neither implementing a step-by-step planned activity, nor is it leaving the children totally free to work as they wish with a predesigned activity. The real role of the teacher in this approach is to guide children and give them opportunities to make discoveries (DeVries et al., 2002). Thus, what needs to be stressed is the need for the teachers who defend working with structured activities to clearly state their role in these activities. The following quotation offers important clues in understanding the tendencies of a teacher who holds this view:

A structured activity involves encouraging children to study by offering them materials and environmental support, and by telling them how to do what. I plan my activities beforehand. The 2006 Preschool Curriculum also mandates this. But I often make an effort to join in the activity. Most of my colleagues don't do so. They direct activities by giving instructions from the outside. (B1)

Two main concepts are worthy of attention in this quotation. One is Preschool Curriculum and the other is participating in activities. The 2006 Preschool Curriculum followed in the kindergartens and preschools affiliated with the Turkish Ministry of National Education is a child-centered and developmental program. Its main aim is to support children's 
cognitive, affective and psychomotor development via activities. The 2006 Preschool Curriculum states that teachers' daily plans should support all of children's developmental areas, ensure their active participation in activities, and construct their knowledge. The curriculum also emphasizes the need for involving children in teachers' planning process, and allowing them to pursue their plans, ask questions, do research, make discussions and produce (MEB, 2006). It is also mentioned in the curriculum that offering children ready environments or processes and continually guiding them is against the main approach of the curriculum, and teachers are strongly advised to take this into account as they prepare their plans. However, although teachers know that the Preschool Curriculum is a developmental one, they believe to the contrary of its requirements that the Ministry of Education is asking them to make plans which include detailed preparations of each stage of the lesson. Thus, it would not be wrong to say that teachers have a misperception about what is expected of them regarding the implementation of the curriculum. This misperception causes them to mostly plan structured activities, which inevitable leads to teacher-centered activities and perhaps to the exclusion of the teacher from the activity. On the other hand, child-centered teachers who follow the constructivist approach overcome this disadvantage by personally becoming engaged in the activities as a group member and acting as a participant rather than a leader. Teacher B1 has this tendency, as shown by his statement that "I often make an effort to join in the activity". This statement is also in agreement with the sociocultural constructivist view, which stresses the importance of interacting with teachers, other adults and peers in child learning (Fosnot \& Perry, 2005; Nuttall, 2003; Airasian \& Walsh, 1997). Indeed, it is recommended that in constructivist preschool classrooms, teachers use the observation and question-answer techniques to interact with children, adapt instruction to suit children's interests and understanding, and create a cooperative and thought-provoking atmosphere in which children can construct their knowledge (DeVries et al., 2002).

\subsection{Learning with Open-ended Activities}

Most preschool teachers (A1, A3, A4, A5, B2, B3, B4) mentioned that open-ended activities are needed to follow the constructivist approach in preschool classrooms. This refers to merely determining an activity which helps the achievement of selected objectives from the curriculum, and letting children launch it with guidance from the teacher. In such an approach, how an activity will ensue and end depends totally on the children. Teachers are of the opinion that children can only discover, discuss, decide, and construct their learning in such a process. However, they also state that in the current situation, the plans that the Ministry of National Education demands do not allow this process. They argue that instead of planning how to start, develop and end an activity step-by-step beforehand, it would be best to only start it and offer alternatives so that children can shape the rest. The literature also supports this view by stating that teachers who are used to directing students and teaching by telling should accept once they shift to constructivist teaching that child learning is brought about not by themselves but the student (DeVries et al., 2002).

As discussed in the two themes above, preschool teachers think that, contrary to the main approach of the curriculum they are using, they are forced to make plans that involve teacher direction and not guidance, and that necessitate organization of the learning process by the teacher. However, it is worth noting that they tend to prepare activities where children are initiators and teachers are participants.

Even though the cognitive and social constructivist approaches emphasize different elements in learning, their main argument about the acquisition of knowledge or the achievement of learning is actually the same. This argument is that knowledge cannot be transmitted from the outside; it has to be a personally constructed process. Piaget contends that individuals construct their knowledge when they organize the raw information that they receive in their brains or when they do reorganization (Von Glasersfeld, 2005). Vygotsky (1997) on the other hand, sees interaction or cooperation as a major method in learning and emphasizes language development more. It has been proposed that these two views on the constructivist approach can be combined in the classroom, and that such a combination is even a prerequisite to ensuring the best individual development in students (Powell \& Kalina, 2009). This study has shown that the views of preschool teachers about how children learn mostly resemble the sociocultural constructivist view. More claims were made about the importance of children's social environment in learning and acquiring knowledge. However, the teacher misconception that the preschool curriculum requires structured activities (where the teacher is dominant in all stages) turns them into "managers" rather than "participants" in the learning process. Therefore, preschool teachers should be better informed about the need to plan lessons which reflect the main approach and theoretical characteristics of the curriculum they are following. On the other hand, the teacher belief that effective learning can be achieved through activities planned in collaboration with children and with the participation of both teachers and students shows that not everything they know about the constructivist approach is wrong. Because this study is a qualitative one, its results are naturally limited. However, the result that the sociocultural view is more prevalent in supporting young children's learning and development offers important clues about teachers' pedagogical views. 


\section{References}

Airasian, P. W., \& Walsh, M. E. (1997). Constructivist cautions, Phi Delta Kappan, 78(6), 444-449.

ASA (1998). What Are Focus Groups? Pamphlet of American Statistical Association Series. Retrieved from http://www.amstat.org/sections/srms/brochures/focusgroups.pdf.

Brooks, J. G., \& Brooks, M. G. (1993). In search of understanding:The case for constructivist classrooms. USA:Association for Supervision and Curriculum Development.

DeVries, R., Zan, B., Hildebrant, C., Edmiaston, R., \& Sales, C. (2002). Developing constructivist early childhood curriculum:Practical principles and activities. New York: Teachers College Press.

Duffy, T. M., \& Cunningham, D. J. (1996). Constructivism: Implications for the design and delivery of instruction. In David H. Jonassen (Ed.), Handbook of research for educational communications and technology (pp. 170-198). New York, USA: Macmillan Library Reference.

Epstein, M. (2002). Constructivism. http://tiger.towson.edu/users/mepste1/researchpaper.htm

Fosnot, C. T. (2005). Preface. In C. T. Fosnot (Ed.), Constructivism: Theory, perspectives, and practice (2nd ed., pp. ix-xii). New York: Teachers College Press.

Fosnot, C. T., \& Perry, R. S. (2005). Constructivism:A psychological theory of learning. In C.T. Fosnot (Ed.), Constructivism: Theory, perspectives, and practice (2nd ed., pp. 8-38). New York: Teachers College Press.

Hatch, J. A. (1989). Alone in a crowd: Analysis of secondary adjustments in a kindergarten classroom. Early Child Development and Care, 44, 39-49. http://dx.doi.org/10.1080/0300443890440105

Hedges, H. (2000). Teaching in early childhood:Time to merge constructivist views so learning through play equals teaching through play, Australian Journal of Early Childhood, 25(4), 16-21.

Lash, M. (2008). Classroom community and peer culture in kindergarten, Early Childhood Educational Journal, 36(1), 33-38. http://dx.doi.org/10.1007/s10643-008-0247-2

Mallory, B. L., \& New, R. S. (1994).Social constructivist theory and principles of inclusion:Challenges for early childhood special education, The Journal of Special Education, 28(3), 322-337. http://dx.doi.org/10.1177/002246699402800307

MEB (2006). 36-72 aylık çocuklar için Okul Öncesi Eğitim Programı (Preschool Curriculum for 36-72 month- old children-Ministry of National Education). Ankara, Türkiye.

Nuttall, J. (2003). Influences on the Co-construction of the teacher role in early childhood curriculum: Some examples from a New Zealand childcare centre, International Journal of Early Years Education, 11(1), 23-31. http://dx.doi.org/10.1080/0966976032000066064

Powell, K. C., \& Kalina, C. J. (2009). Cognitive and social constructivism: Developing tools for an effective classroom, Education, 130(2), 241-250. ERIC Number: EJ871658

Senemoğlu, N. (1997).Gelişim öğrenme ve öğretim: Kuramdan uygulamaya (Development, learning and teaching.From theory to practice).Ankara, Türkiye:Spot Matbaacılık.

Stewart, D. W., Shamdasani, P. N., \& Rook, D. W. (2007). Focus groups theory and practice. Applied social research methods series, Volume 20, Sage Publications, Inc.

Watson, J. (2001). Social constructivism in the classroom, Support for Learning, 16(3), 140-147. http://dx.doi.org/10.1111/1467-9604.00206

Vanderstraeten, R., \& Biesta, G. (2005). Constructivism, educational research, and John Dewey, Karl Jaspers Forum, 8. Retrieved from http://www.kjf.ca/76-TAVAN.htm

Von Glasersfeld, E. (2005) Introduction: aspects of constructivism. Chapter One in C. T. Fosnot (Ed.), Constructivism: Theory, perspectives, and practice (2nd ed., pp.3-8). New York: Teachers College Press.

Vygotsky, L. S. (1997). Interaction between learning and development. In M.Gauvain and M.Cole (Eds.), Readings on the development of children (2nd ed., pp. 29-36). New York: W.H. Freeman and Company. Retrieved from http://www.psy.cmu.edu/ siegler/vygotsky78.pdf

\section{$(\mathrm{Cc}) \mathrm{BY}$}

This work is licensed under a Creative Commons Attribution 3.0 License. 